\title{
Determination of Minimum Inhibitory Concentration of Different Antibiotic Groups in Clinical Isolates of Pseudomonas aeruginosa Containing $p-A m p C$ and Their Relationship with Antibiotic Resistance Pattern
}

\author{
Hamed Tahmasebi ${ }^{1}$, Mohammad Yousef Alikhani ${ }^{2}$, Sanaz Dehbashi $^{3}$, Mohammad Reza \\ Arabestani ${ }^{4,5, *}$ \\ ${ }^{I}$ MSc in Microbiology, Department of Microbiology, School of Medicine, Zahedan University of Medical Sciences, Zahedan, \\ Iran \\ ${ }^{2}$ Professor, Department of Microbiology, School of Medicine, Hamadan University of Medical Sciences, Hamadan, Iran \\ ${ }^{3}$ PhD Student in Microbiology, Department of Microbiology, School of Medicine, Hamadan University of Medical Sciences, \\ Hamadan, Iran \\ ${ }^{4}$ Asociate Peofessor, Department of Microbiology, School of Medicine, Hamadan University of Medical Sciences, Hamadan, \\ Iran \\ ${ }^{5}$ Asociate Peofessor, Nutrition Health Research Center, Hamadan University of Medical Sciences, Hamadan, Iran \\ * Corresponding Author: Mohammad Reza Arabestani, Department of Microbiology, Hamadan University of Medical \\ Sciences, Hamadan, Iran. Email: mohammad.arabestani@gmail.com
}

Received: 05.09.2017

Accepted: 15.01.2018

How to Cite this Article: Tahmasebi H, Alikhani MY, Dehbashi S, Arabestani MR. Determination of Minimum Inhibitory Concentration of Different Antibiotic Groups in Clinical Isolates of Pseudomonas aeruginosa Containing $p-A m p C$ and Their Relationship with Antibiotic Resistance Pattern. Avicenna J Clin Med. 2018; 24(4): 277-284. DOI: $10.21859 /$ ajcm.24. 4.277 .

\section{Abstract}

Background and Objective: $A m p C$-type beta-lactamases have been implicated in group $\mathrm{C}$ of Amber, which includes EBC, CIT, MOX, FOX, $D H A$, and $A C C$. The active presence of these plasmid genes in clinical isolates of P.aeruginosa has resulted in resistance to a wide range of antibiotics. Therefore, we aimed to determine the minimum inhibitory concentrations (MIC) of different antibiotic groups in clinical isolates of $P$. aeruginosa carrying $A m p C$ enzyme and study their relationship pattern. Materials and Methods: In this descriptive study, the MIC of $95 P$. aeruginosa isolates was determined using E-test for cefocytosine, cefpodoxime, cefotaxime, ceftazidime, ciprofloxacin, colicitin, aztreonam, and ceftriaxone antibiotics (Liofilchem, Italy). Multiplex polymerase chain reaction was used to amplify and identify plasmid genes. The Chi-squared test was used to determine the relationship between variables.

Results: Of the $95 P$. aeruginosa isolates, 95 (100\%) isolates were resistant to cefoxitin, $79(83.5 \%)$ isolates to cefpodoxime, $2(2.1 \%)$ isolates to ceftazidime, $87(81.57 \%)$ isolates to ceftriaxone, and $22(23.15 \%)$ isolates were resistant to aterranum, but none of the isolates was resistant to colistin. In addition, $21(22.1 \%)$ isolates had FOX gene, $13(11.57 \%)$ isolates had $A A C$ gene, 7 (36.6\%) isolates had MOX gene, 4 (21.4\%) isolates had CIT gene, $2(2.1 \%)$ isolates had DHA gene, and $1(1.05 \%)$ isolate had $E B C$ gene. It is worth mentioning that there was a significant relationship between the presence of plasmid genes and antibiotic resistance (level of significance: $\mathrm{P} \leq 0.05)$.

Conclusion: The presence of the genes encoding the AmpC enzyme can provide the ground for resistance to a broad range of antibiotics.

Keywords: Beta-lactamase Enzyme, Beta-lactamase Resistance, Minimum Inhibitory Concentration, Pseudomonas aeruginosa 


\title{
تعيين حداقل غلظت مهارى تروههاى مختلف آنتىبيوتيكهاى بتالاكتامى در ايزولههاى بالينى سودوموناس آئروزينوزاى حامل AmpC الكوى مقاومت آنتىبيوتيكى
}

\author{
حامد طهماسبى'، محمد يوسف عليخانى '، ساناز دهباشى '، محمد رضا عربستانى F،ه،* \\ ' كارشناس ارشد، گروه ميكروبشناسى، دانشكده يزشكى، دانشكاه علوم يزشكى زاهدان، زاهدان، ايران

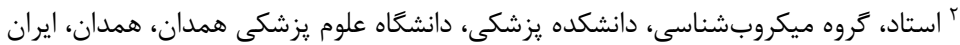

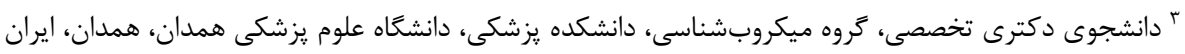

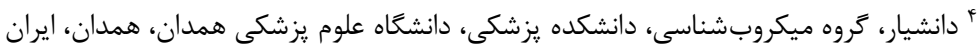

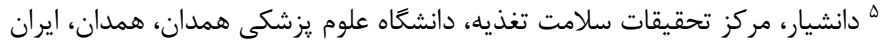
* نويسنده مسئول: محمد رضا عربستانى، دانشخاه علوم يزشكى همدان، دانشكده يزشكى، كروه ميكروبشناسى، همدان، ايران. ايميل: mohammad.arabestani@gmail.com

جكيده

سابقه و هدف: بتالاكتاماز نوع AmpC در كروه Amber Class C قرار مى ميرد و شامل: CIT، EBC

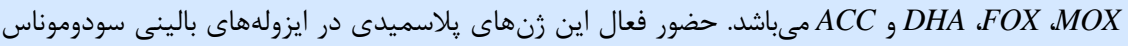

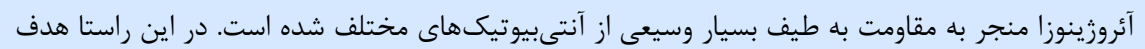

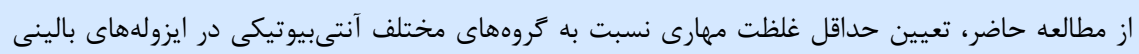

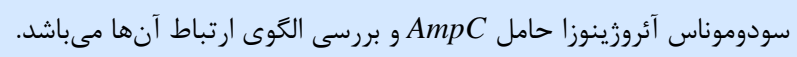

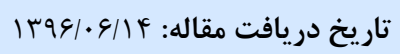

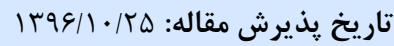
تمامى حقوق نشر براى دانشكاه علوم يزشكى همدان محفوظ است.

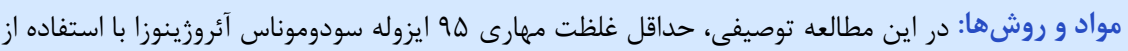

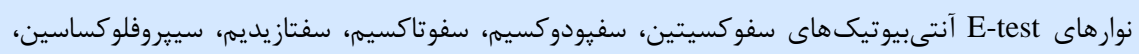

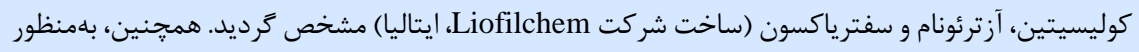

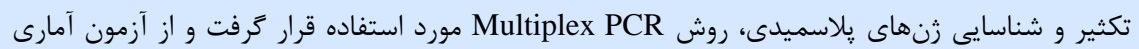
Chi-Square

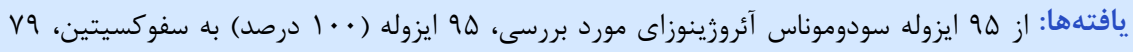

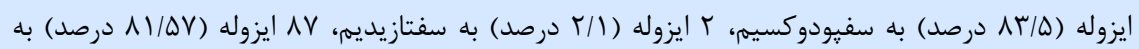

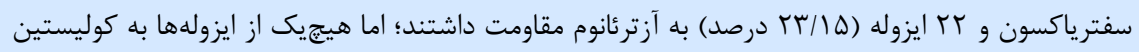

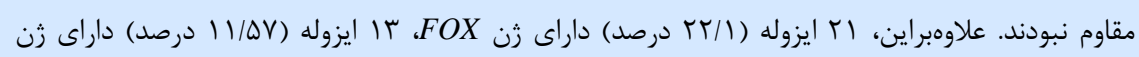

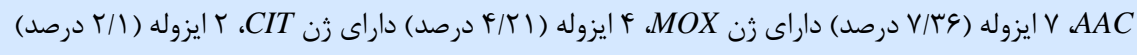

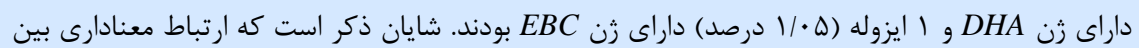

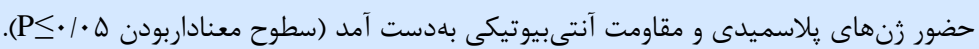

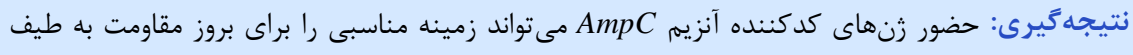

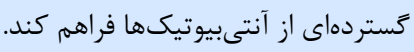

وازگًان كليدى: آنزيم بتالاكتاماز، حداقل غلظت مهارى، سودوموناس آئروزينوزا، مقاومت بتالاكتامى
كه قادر هستند آنتىبيوتيكهاى بتالاكتام را هيدروليز كنند و سبب بىاثرشدن اين تركيبات شوند [1]]. سودوموناس آئروزينوزا

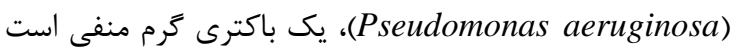

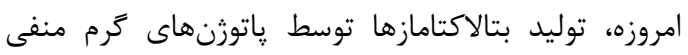

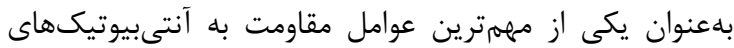

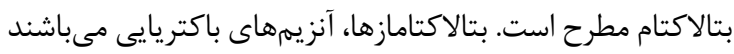


بيشتر آنزيمهاى AmpC، سفالوسيوريناز هستند؛ اما تاحدى

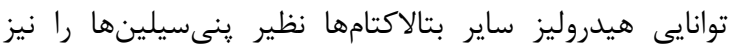

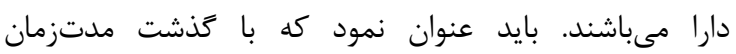

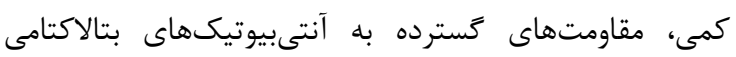

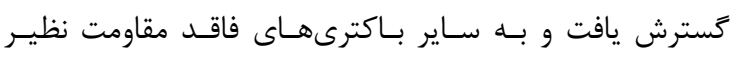

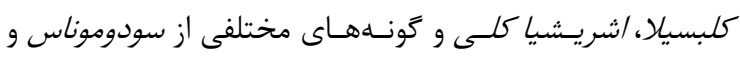

آسينتوباكتر منتقل كرديد [ه].

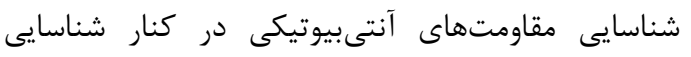

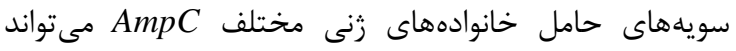

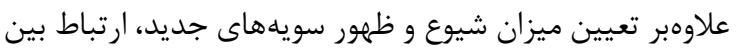

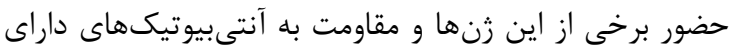

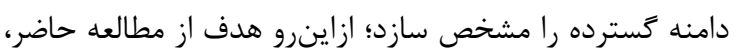

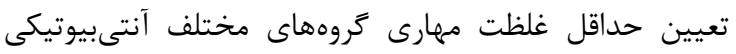

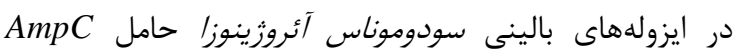

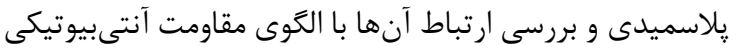
بود تا بدينطريق، اين ارتباط آمارى ارزيابى شود.

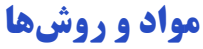

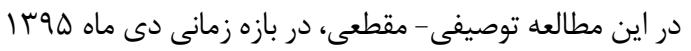

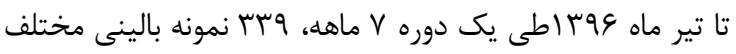

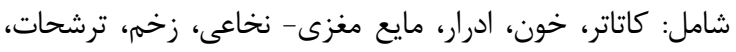

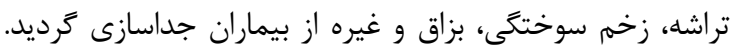

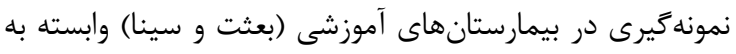

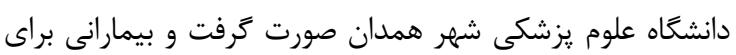

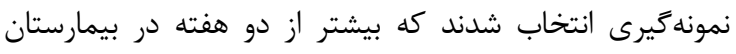

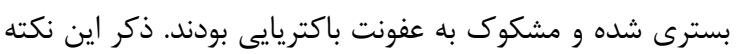

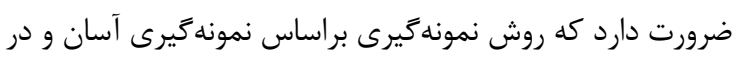

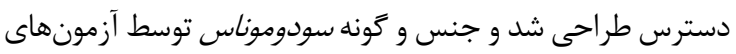

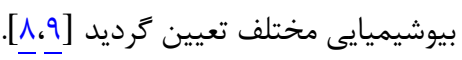

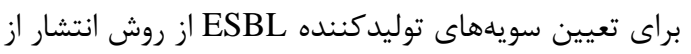

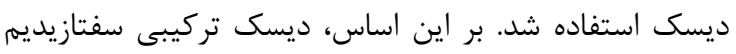

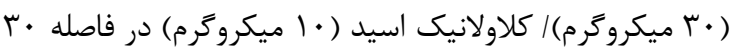

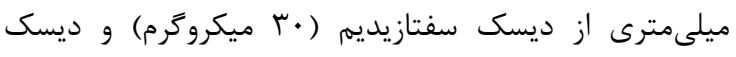

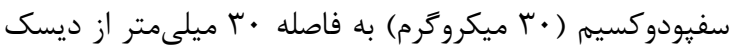

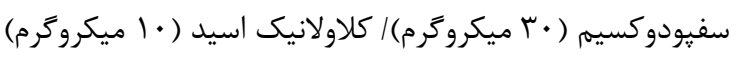

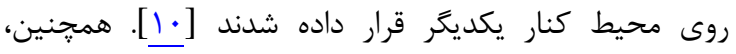

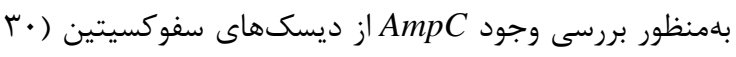

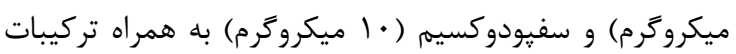

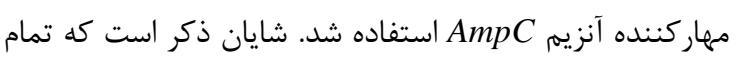

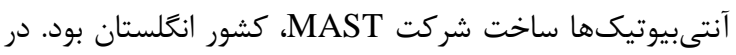

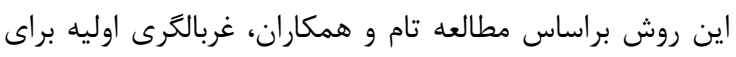

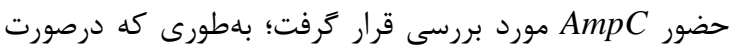

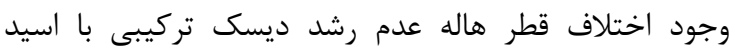
كلاولانيك با قطر هاله عدم رشد ديسك فاقد اسيد كلاولانيك به ديه
كه بهعنوان عاملى مهم در ايجاد عفونت در بيماران بسترى و نيز

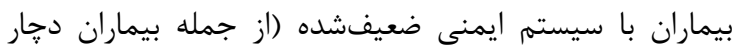

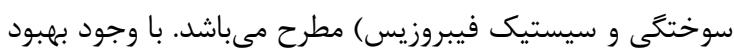

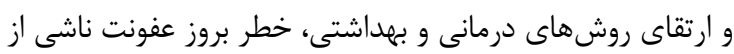
سودوموناس آئروزينوزا در بيماران بسترى در بخد بنش

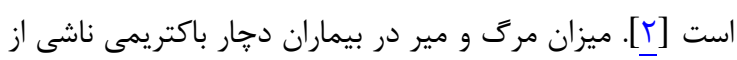

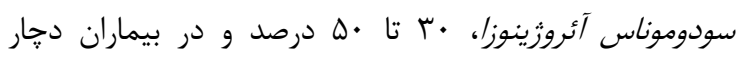

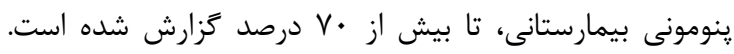

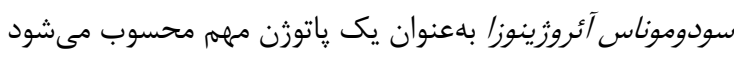

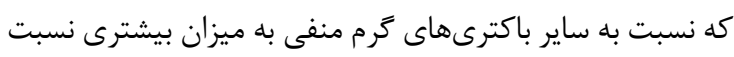

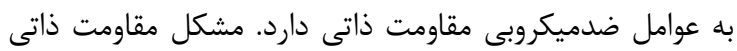

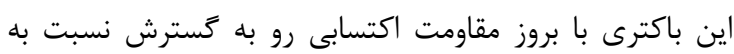

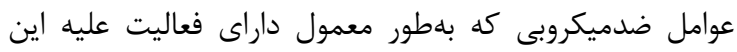

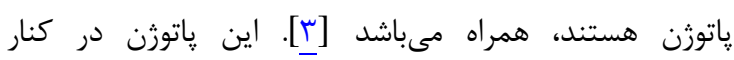
باكترىهايى مانند /شريشيا كولى (Escherichia coli)، كلبسيلا

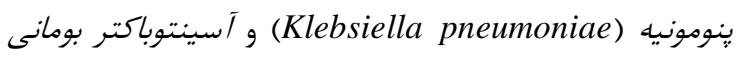
مى تواند زمينهساز عفونتهاى (Acinetobacter baumannii)

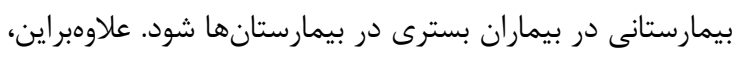

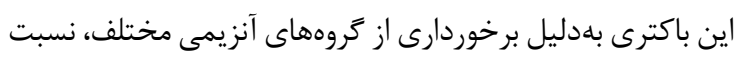

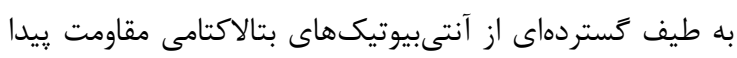

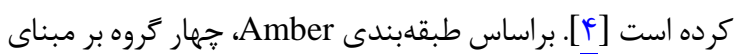

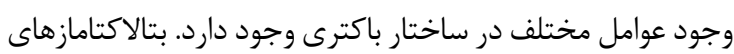

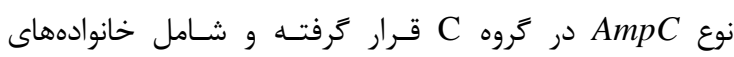

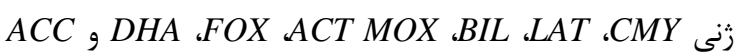
مسىباشـند كه در ايـن ميـان،

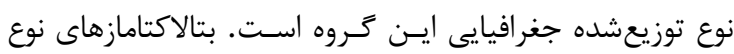
AmpC

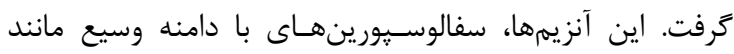

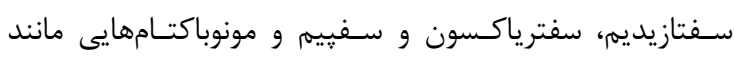

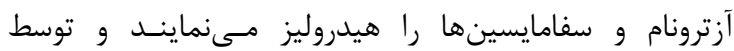

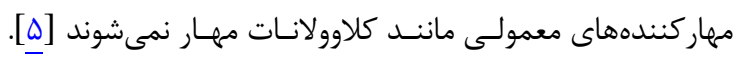

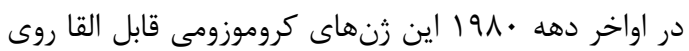

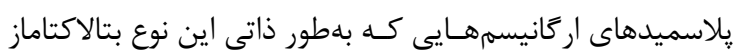

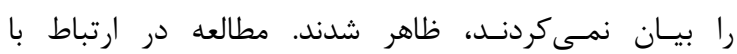

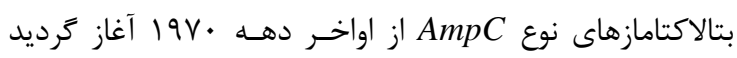

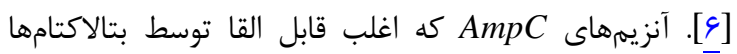

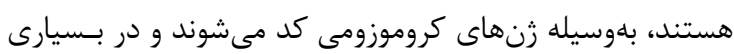

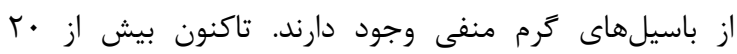

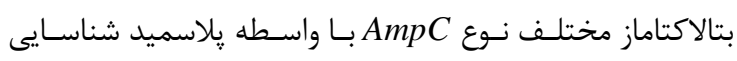

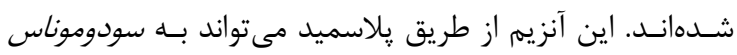

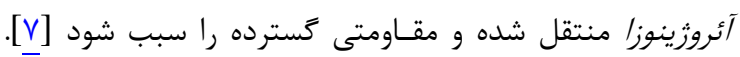

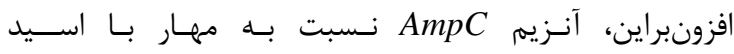

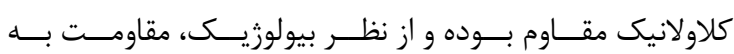
سفامايسينها را بهخوبى ايجـاد مى كند. لازم به ذكر است كه 
استفاده از يرايمرهاى موجود در جدول ا و همجنين تكنيك

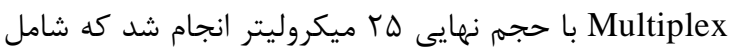

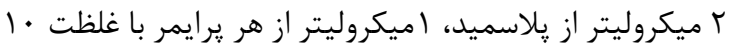

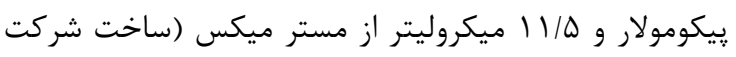
Ampliqon

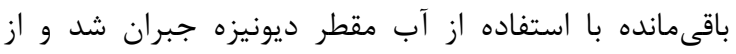
مخلوط PCR فاقد پيلاسميد بهعنوان كنترل منفى استفاده كرديد.

سيس، آزمون PCR براى زنهاى AmpC با استفاده از دستخاه ترموسايكلر (ساخت شركت BioRad، كشور آمريكا)

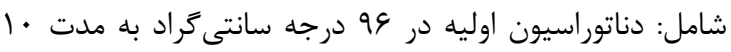

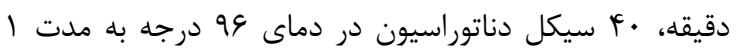
دقيقه، مرحله اتصال يرايمر در دماى الو درجه دئه سانتى

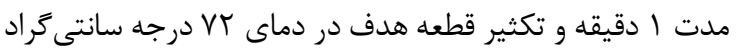

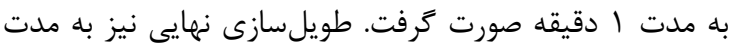

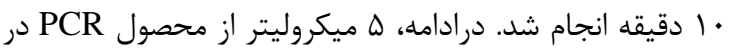

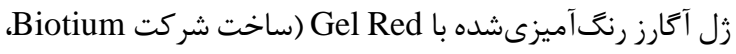

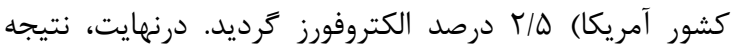

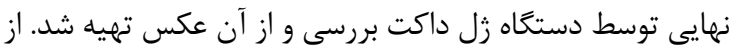

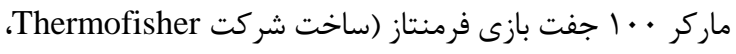

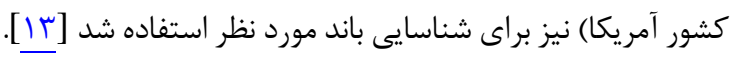

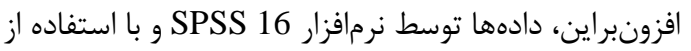
آزمون Chi-Square و ضريب كايا (Kappa Coefficient) تجزيه و تحليل شدند و مقادير (ه • P (P) ) بهعنوان شاخص معناداربودن درنظر كرفته شد. تُدئ
ميزان بيشتر يا مساوى ه ميلىمتر، آن نمونه از نظر حضور ESBL

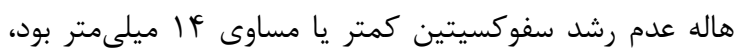
توليدكننده AmpC درنظر كرفته مىشد [11]. از سوى ديخر، حداقل غلظت مهارى براى آنتىبيوتيكهاى سفوكسيتين، سفيودوكسيم، سفوتاكسيه، سفتازيديم، سييرو

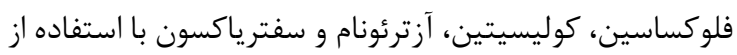

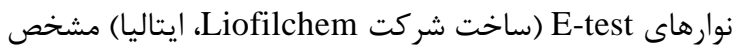
كرديد. همجنين، بهمنظور تعيين حداقل غلظت مهارى از سويه

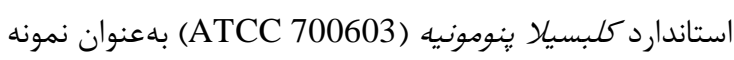
كنترل مثبت و از سويه استاندارد سودوموناس آئروزينوزا

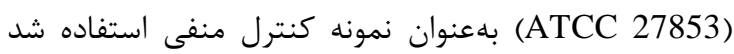

[11.11]

علاوهبراين بهمنظور استخراج پيلاسميد، از كيت استخراج

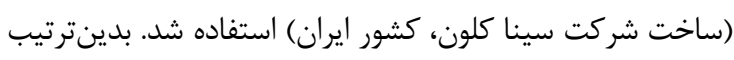

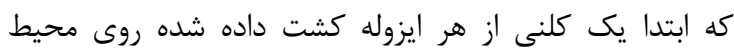

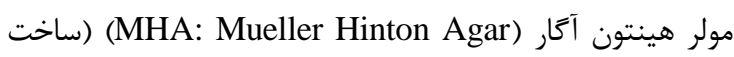

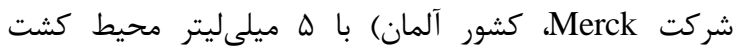

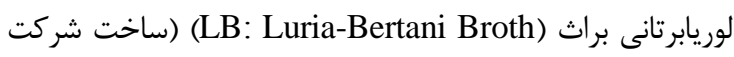
Sigma-Aldrich دماى MV درجه سانتى گراد انكوبه گرديد. سيس، مراحل استخراج

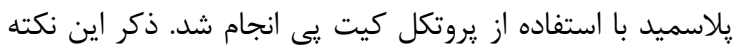

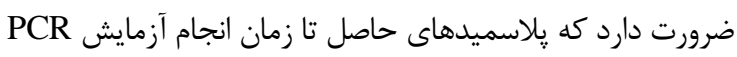
در دماى • r- درجه ذخيرهسازى گرديد [ ·1].

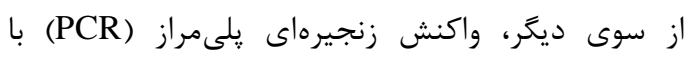

جدول ا: مشخصات يرايمرهاى مورد استفاده براى شناسايى زن هاى AmpC در ايزولههاى سودوموناس آئروزينوزا

\begin{tabular}{|c|c|c|c|c|c|}
\hline منبع & $\begin{array}{l}\text { شماره دسترسى در } \\
\text { GenBank }\end{array}$ & 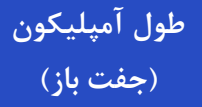 & توالى نوكلئوتيدها & نام برايمر & ثن \\
\hline$[\underline{[1, T}$ & $\underline{D 13304}$ & $\Delta T$. & $\begin{array}{l}\text { GCT GCT CAA GGA GCA CAG GAT } \\
\text { CAC ATT GAC ATA GGT GTG GTG C }\end{array}$ & $\begin{array}{l}\text { MOXMF } \\
\text { MOXMR }\end{array}$ & $M O X$ \\
\hline$[\underline{[1, T}$ & $\underline{\mathrm{X} 78117}$ & far & $\begin{array}{l}\text { TGG CCA GAA CTG ACA GGC AAA } \\
\text { TTT CTC CTG AAC GTG GCT GGC }\end{array}$ & $\begin{array}{l}\text { CITMF } \\
\text { CITMR }\end{array}$ & CIT \\
\hline$[1, \mu]$ & $\underline{Y 16410}$ & $f \cdot \Delta$ & $\begin{array}{l}\text { AAC TTT CAC AGG TGT GCT GGG T } \\
\text { CCG TAC GCA TAC TGG CTT TGC }\end{array}$ & $\begin{array}{l}\text { DHAMF } \\
\text { DHAMR }\end{array}$ & $D H A$ \\
\hline$[\underline{[1, T}$ & $\underline{\text { M37839 }}$ & $r \cdot r$ & $\begin{array}{l}\text { TCG GTA AAG CCG ATG TTG CGG } \\
\text { CTT CCA CTG CGG CTG CCA GTT }\end{array}$ & $\begin{array}{l}\text { EBCMF } \\
\text { EBCMR }\end{array}$ & $E B C$ \\
\hline$[\underline{[1,}]$ & $\underline{\mathrm{X} 77455}$ & 19. & $\begin{array}{l}\text { AAC ATG GGG TAT CAG GGA GAT G } \\
\text { CAA AGC GCG TAA CCG GAT TGG }\end{array}$ & $\begin{array}{l}\text { FOXMF } \\
\text { FOXMR }\end{array}$ & FOX \\
\hline$[\underline{[1,4}$ & $\underline{\text { AJ133121 }}$ & res & $\begin{array}{l}\text { AAC AGC CTC AGC AGC CGG TTA } \\
\text { TTC GCC GCA ATC ATC CCT AGC }\end{array}$ & $\begin{array}{l}\text { ACCMF } \\
\text { ACCMR }\end{array}$ & $A C C$ \\
\hline
\end{tabular}

يافته ها

ايزوله (ه/ه درصد) از ترشحات و \& ايزوله (س/و درصد) از ساير

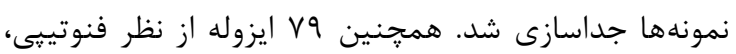

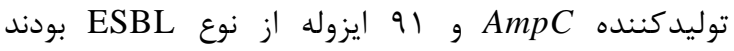
(جدول r). به لحاظ حداقل غلظت مهارى نيز و 9 ايزوله داراى
از هو ايزوله بالينى سودوموناس آئروزينوزا، وب ايزوله ( )

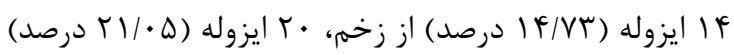

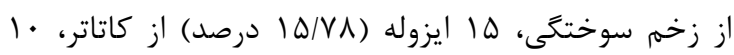




\begin{tabular}{|c|c|c|}
\hline \multicolumn{3}{|c|}{ سودوموناس آئروزينوزا (n=9ه) } \\
\hline$\left(\mathrm{n}=\boldsymbol{p q}^{q}\right) A m p C$ & $(\mathbf{n}=91)$ ESBL & جنسيت \\
\hline \multicolumn{3}{|c|}{ تعداد (درصد) } \\
\hline$(\Lambda 1 / r \mu) F$. & $(V \& / 9 Y) V$. & زن \\
\hline$(1 \wedge / 48) 9$ & $(Y r / \cdot V) Y I$ & مرد \\
\hline
\end{tabular}

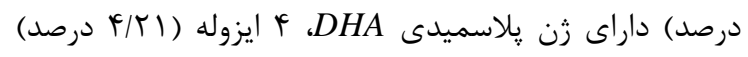

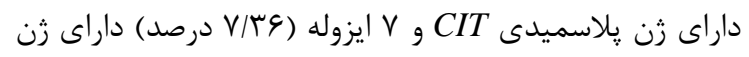

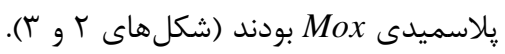

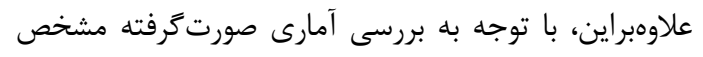

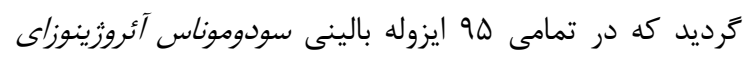

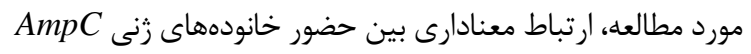

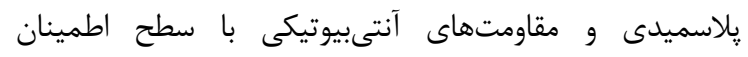
بهدست آمد كه نشانكر آن بود كه سويههاى داراى

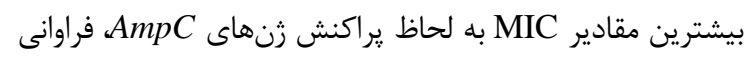

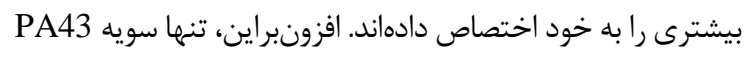

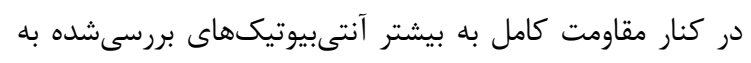

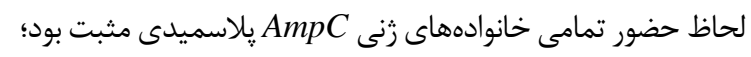

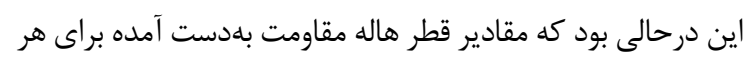

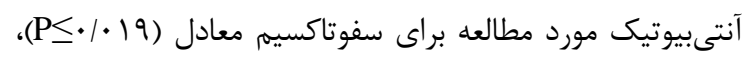

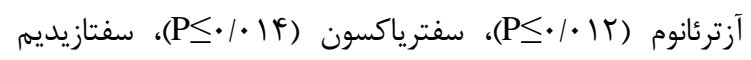

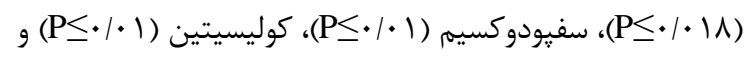

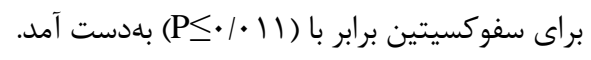

حداقل غلظت مهارى بيشتر از f ميكروگرم بر ميلىليتر و

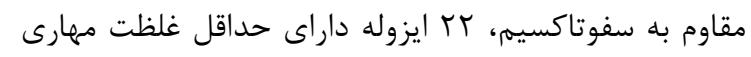

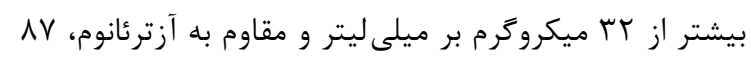

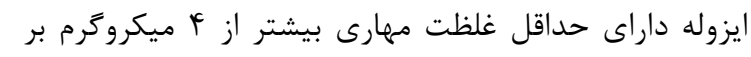

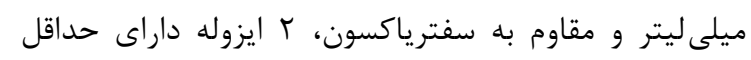

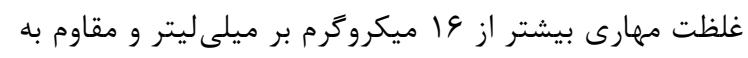

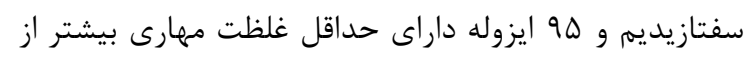

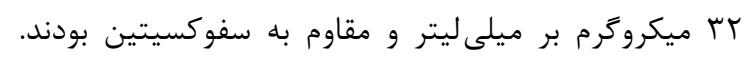

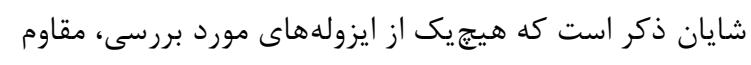

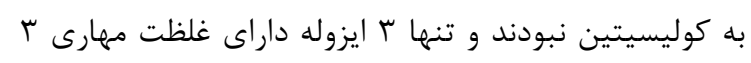

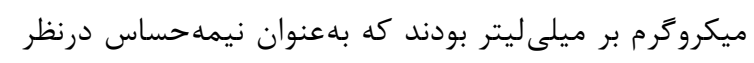
گرفته شدند (شكل (1) (جدول برم).

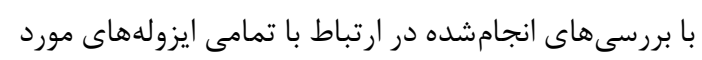

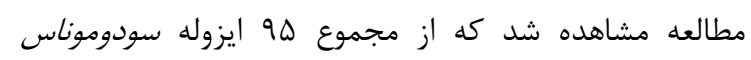

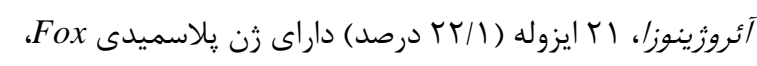

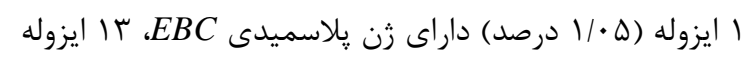

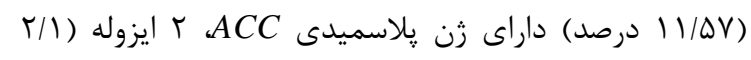

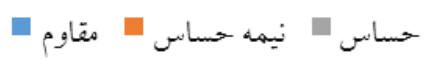

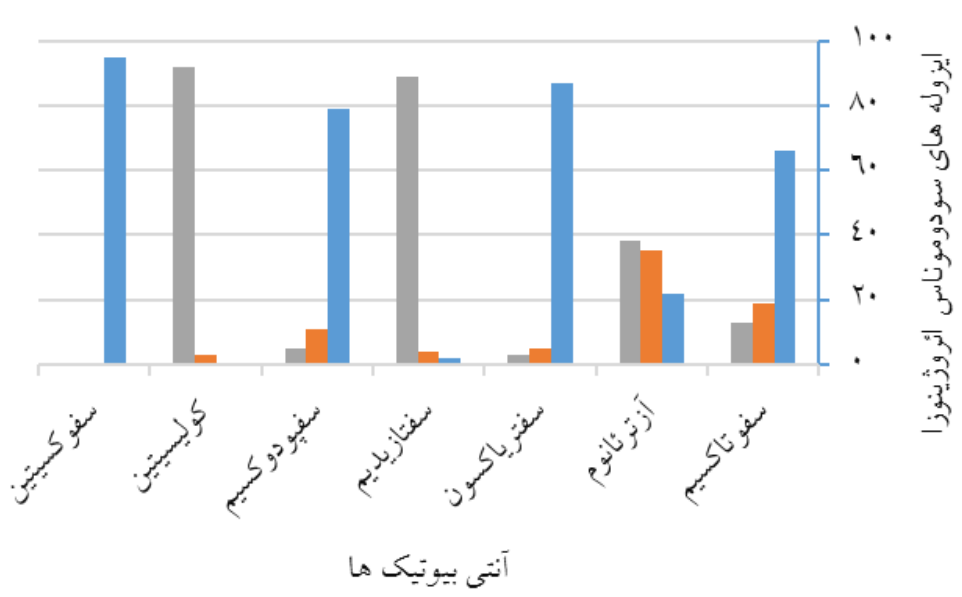

شكل ا: حداقل غلظت مهارى ايزولههاى بالينى سودوموناس آئروزينوزا

و سفالوسيورينها (بهجز سفييروم و سفيیم) مى گردد. AmpC

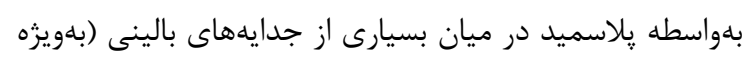

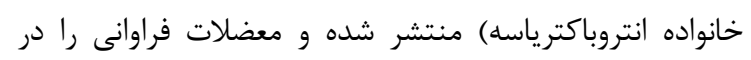

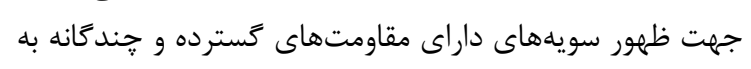

AmpC مقاومت به بتالاكتامها بلهواسطه حضور آنزيم

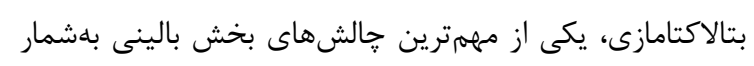

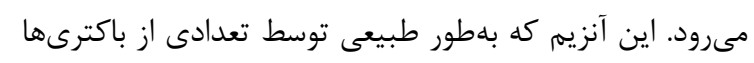
حَرم منفى توليد مىشود، سبب ايجاد مقاومت به به ينىسيلينها 
جدول بّ: فراوانى زنهاى عامل آنزيم AmpC براساس الكوى مقاومت آنتىبيوتيكى در ايزولههاى بالينى سودوموناس آئروزينوزا

\begin{tabular}{|c|c|c|c|c|c|c|c|c|c|c|c|c|c|c|c|c|c|c|c|c|c|c|}
\hline \multirow{3}{*}{ ثعداد } & \multicolumn{21}{|c|}{ فراوانى ايزوله هاى سودوموناس آئروزينوزاى داراى مقاومت } & \multirow{3}{*}{ موردهاى } \\
\hline & \multicolumn{3}{|c|}{ سفوكسيتين } & \multicolumn{3}{|c|}{ كوليستين } & \multicolumn{3}{|c|}{ سفيودوكسيم } & \multicolumn{3}{|c|}{ سفتازيديم } & \multicolumn{3}{|c|}{ سفتر ياكسون } & \multicolumn{3}{|c|}{ آز ترئانوم } & \multicolumn{3}{|c|}{ سفوتاكسيم } & \\
\hline & $\mathbf{S}$ & I & $\mathbf{R}$ & $\mathbf{S}$ & I & $\mathbf{R}$ & $\mathbf{S}$ & I & $\mathbf{R}$ & $\mathbf{S}$ & I & $\mathbf{R}$ & $\mathbf{S}$ & I & $\mathbf{R}$ & $\mathbf{S}$ & I & $\mathbf{R}$ & $\mathbf{S}^{*}$ & $I^{*}$ & $\mathbf{R}^{*}$ & \\
\hline rI & . & - & 9 & 1 & - & . & - & • & f & • & $r$ & . & . & - & 1 & • & r & - & - & 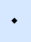 & $r$ & FOX \\
\hline 14 & · & - & $r$ & · & - & . & • & - & 9 & • & - & • & - & - & f & • & $\cdot$ & - & - & $\cdot$ & 1 & $A A C$ \\
\hline V & . & - & 1 & . & - & . & . & - & 1 & . & - & $r$ & - & - & r & · & - & - & - & - & . & $M O X$ \\
\hline$r$ & • & - & $r$ & • & - & • & • & - & • & • & - & • & - & - & • & - & • & - & • & - & · & $D H A$ \\
\hline 1 & • & • & 1 & . & - & . & . & - & . & . & - & • & - & - & - & - & - & • & • & - & · & $E B C$ \\
\hline f & · & • & 1 & . & - & . & • & - & $r$ & • & - & · & - & - & · & • & - & . & . & - & 1 & CIT \\
\hline
\end{tabular}

R: Resistant

I: Intermediate

S: Sensitive

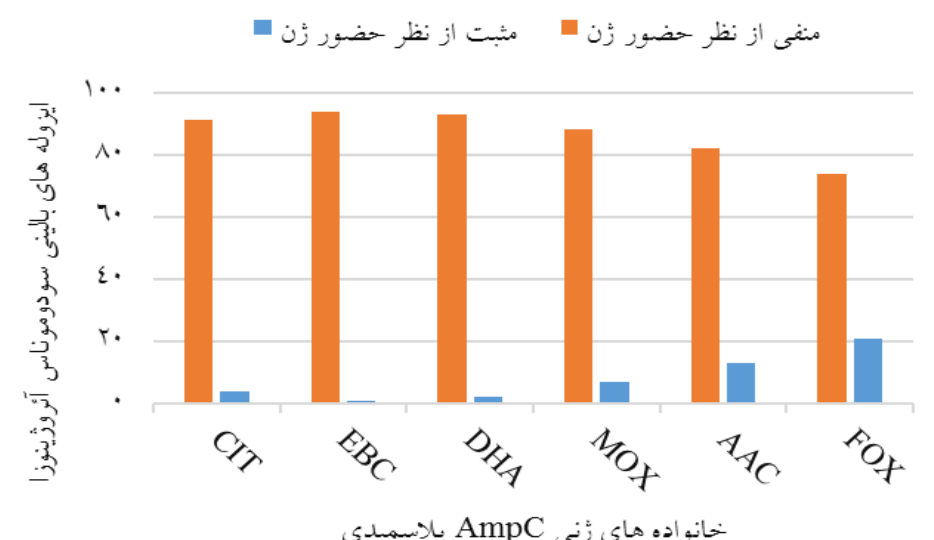

شكل r: فراوانى خانودههاى رنى AmpC

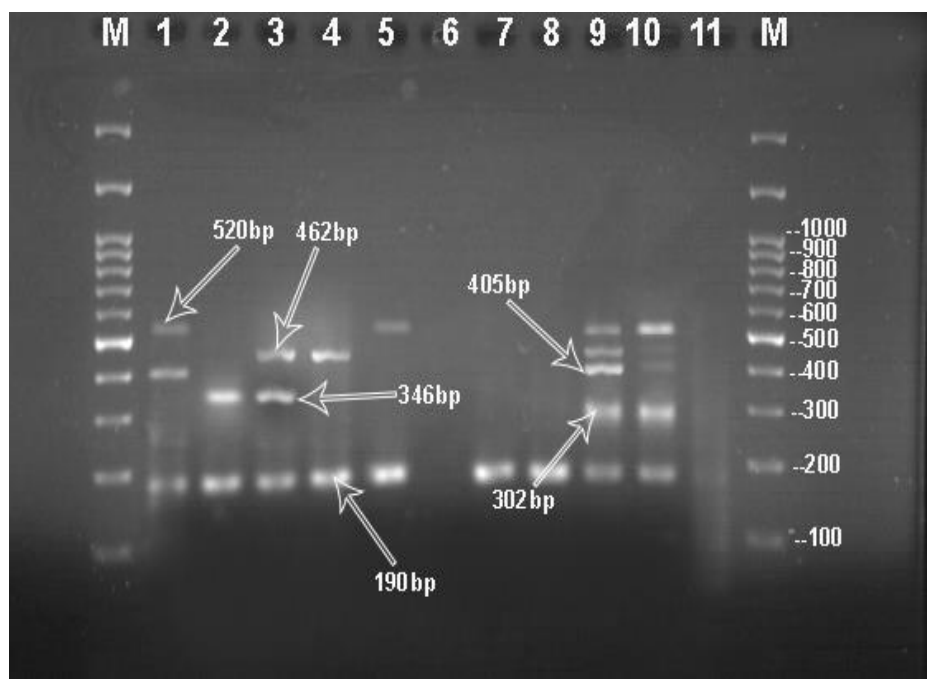

شكل r: نتايج حاصل از تكثير زنهاى خانواده AmpC بر زل آكارز ه/

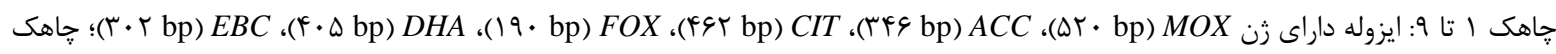

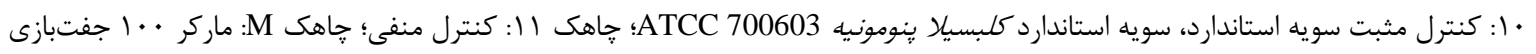

سودوموناس آئروزينوزا يكى از مهممترين باكترىهاى عامل

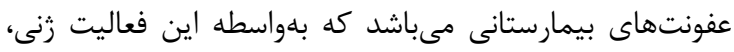

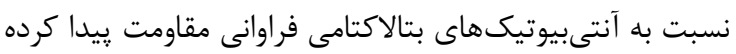

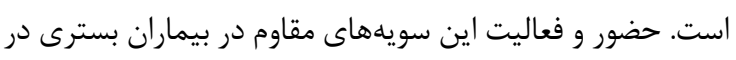

آنتىبيوتيكهاى مختلف ايجاد مى كند.

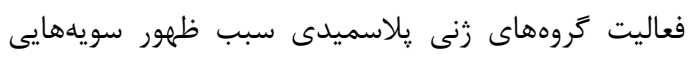

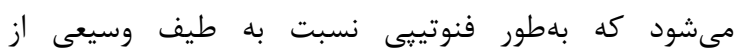
آنتىبيوتيكهاى بتالاكتامى و سفالويورينى مقاومت پِيدا كردهاند. 
سودوموناس آئروزينوز/ طى سالهاى اخير، بهدليل فعاليتهاى

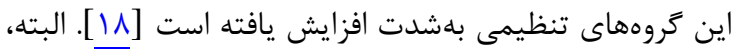

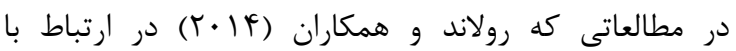

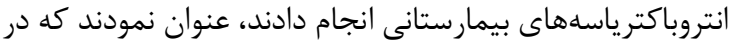

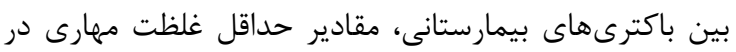

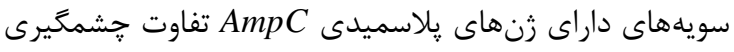

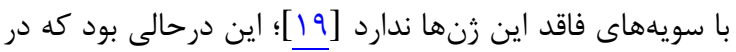

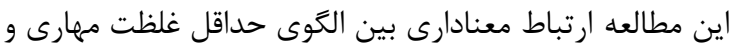

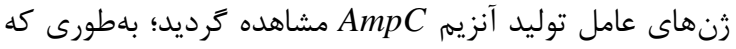

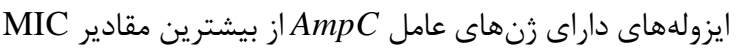

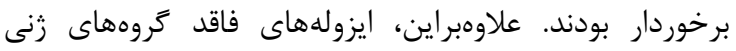

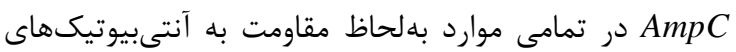

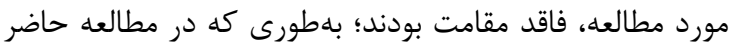

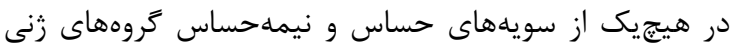

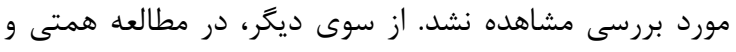

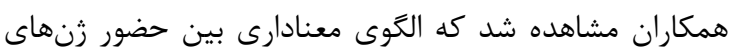

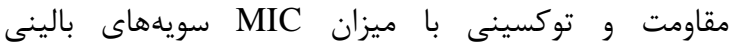

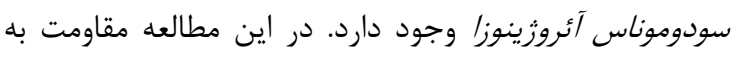

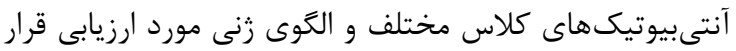

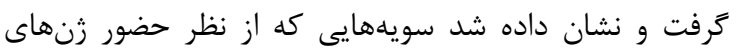

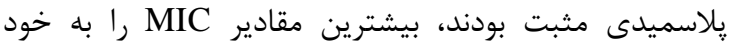

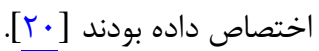

\section{نتيجه تيرى}

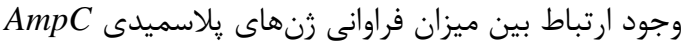

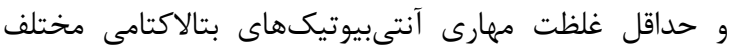

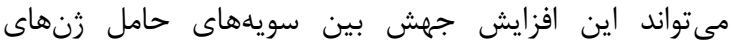

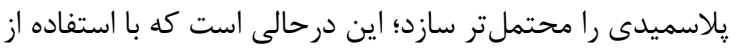

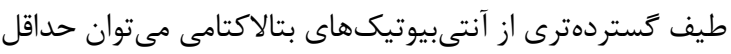

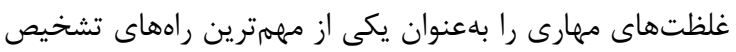

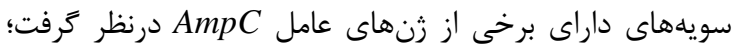

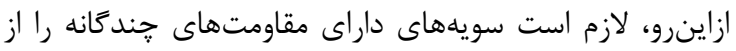
نظر محتملبودن حضور زنهاى كدكننده اين آنزيم مورد توجه

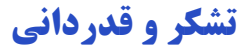

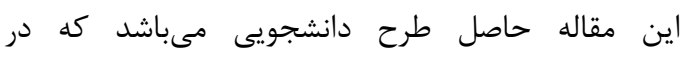

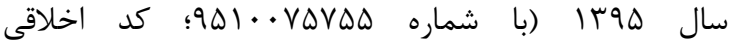

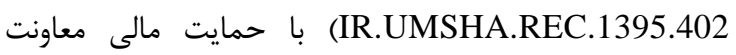
يزوهشى دانشكاه علوم يزشكى همدان به انجام رسيده است.

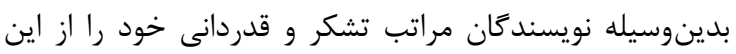

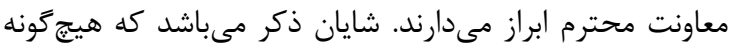
تعارض منافعى كزارش نكرديده است.
بيمارستان مى تواند مسير درمان را با مشكل مواجه سازد. نتايج

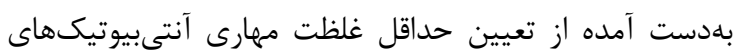

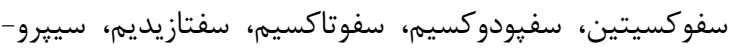

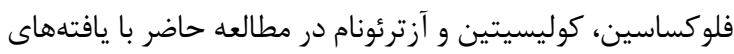

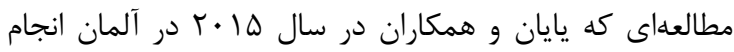

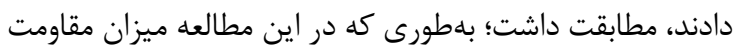

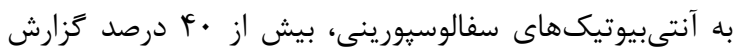

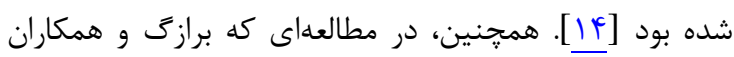

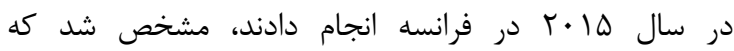

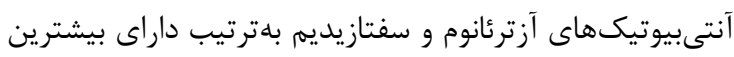

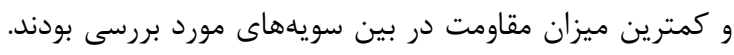

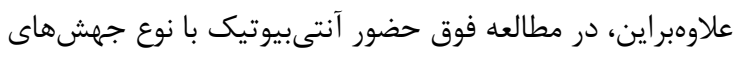

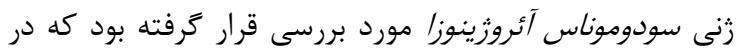

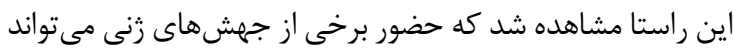

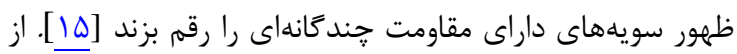

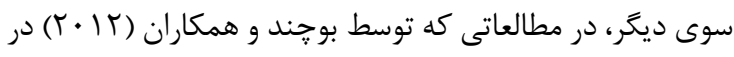

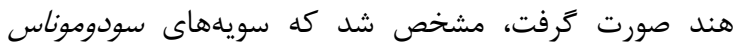

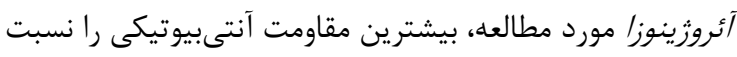

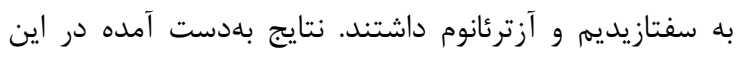

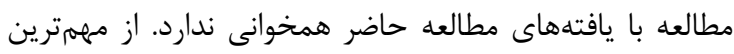

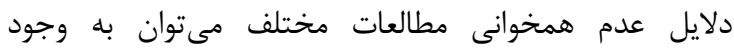

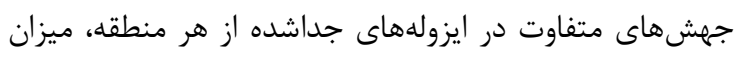

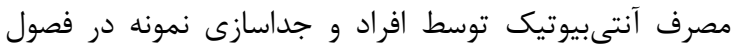

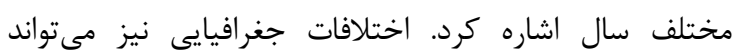

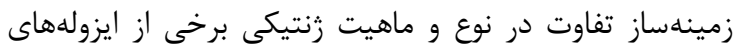

بالينى باشد [19].

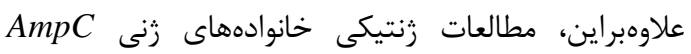

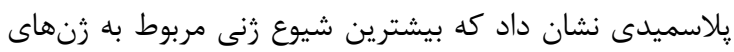
AAC F FOX

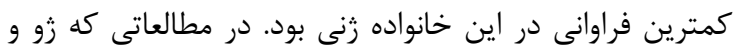

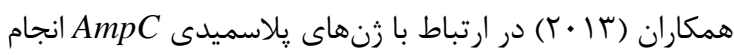

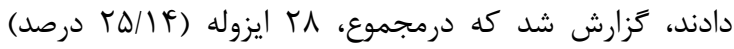

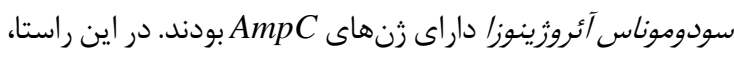

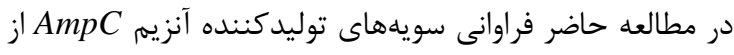

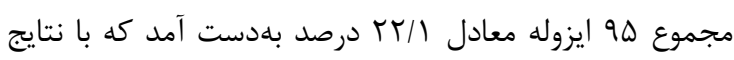

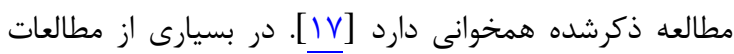

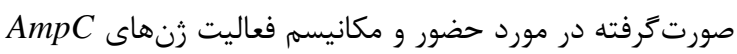

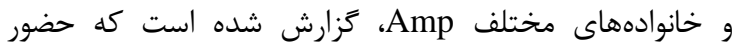

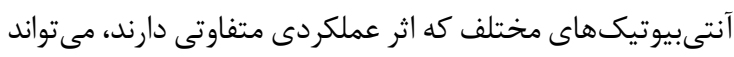
رنهاى تنظيمى خانواده AmpC را به نوعى تغيير دهد كهات

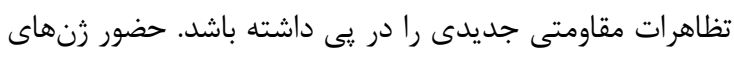

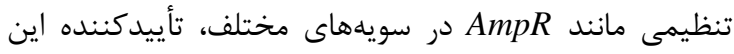

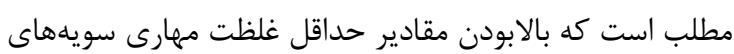




\section{REFERENCES}

1. Japoni-Nejad A, Ghaznavi-Rad E, van Belkum A. Characterization of Plasmid-Mediated AmpC and carbapenemases among Iranain nosocomial isolates of Klebsiella pneumoniae using phenotyping and genotyping methods. Osong Public Health Res Perspect. 2014;5(6):3338. PMID: 25562041 DOI: 10.1016/j.phrp.2014.09.003

2. Arabestani MR, Rajabpour M, Mashouf RY, Alikhani MY, Mousavi SM. Expression of Effulux Pump MexAB-OprM and OprD of Pseudomonas aeruginosa Strains Isolated from Clinical Samples using qRT-PCR. Arch Iran Med. 2015;18(2):102-8.

3. Rajabpour M, Alikhani MY. MIC determination of Pseudomonas aeruginosa strains were isolated from clinical specimens of patients admitted to educational hospitals in Hamedan (90-91). Iran J Microbiol. 2013;7(3):18-25. [Persian]

4. Fazzeli H, Faghri J, Kabiri P, Fatahibafghi M, Arabestani MR. Identification of beta-Lactamase-Producing Pseudomonas aeruginosa with multiple antibiotic resistances. $J$ Isfahan Med School. 2012;29(154):1365-74. [Persian]

5. Reuland EA, Halaby T, Hays JP, de Jongh DM, Snetselaar $\mathrm{HD}$, van Keulen $\mathrm{M}$, et al. Plasmid-mediated $A m p C$ : prevalence in community-acquired isolates in Amsterdam, the Netherlands, and risk factors for carriage. PLoS One. 2015;10(1):e0113033. PMID: 25587716 DOI: 10.1371/ journal.pone. 0113033

6. Reuland EA, Hays JP, de Jongh DM, Abdelrehim E, Willemsen I, Kluytmans JA, et al. Detection and occurrence of plasmid-mediated $A m p C$ in highly resistant gram-negative rods. PLoS One. 2014;9(3):e91396. PMID: 24642853 DOI: 10.1371/journal.pone.0091396

7. Juan C, Macia MD, Gutierrez O, Vidal C, Perez JL, Oliver A. Molecular mechanisms of beta-lactam resistance mediated by $A m p C$ hyperproduction in Pseudomonas aeruginosa clinical strains. Antimicrob Agents Chemother. 2005;49(11): 4733-8. PMID: 16251318 DOI: 10.1128/AAC.49.11.47334738.2005

8. Japoni-Nejad A, Fardmusavi N, Safari M, Kazemian H, Tabibnejad M, Amuzandeh Nobaveh A, et al. Prevalence of plasmid-mediated $A m p C$ B-lactamase genes in clinical isolates of Klebsiella pneumoniae in Arak City, Iran. $J$ Isfahan Med Sch. 2013;31(249):1285-95. [Persian]

9. Tahmasebi H, Adabi J, Shahraki Zahedani S, Zeyni B. Comparison of two methods of direct PCR and PCR with DNA extracted by Kit for detection of OPrL, ExoA, and algD genes in clinical isolates of Pseudomonas aeruginosa. Qom Univ Med Sci J. 2017;11(3):11-21. [Persian]

10. Adabi J, Shahraki Zahedani S, Bokaeian M, Tahmasebi H. An investigation of the prevalence of AmpC-producing Pseudomonas aeruginosa in clinical samples in Zahedan city, Iran. Qom Univ Med Sci J. 2017;11(4):61-71. [Persian]

11. Tam VH, Schilling AN, LaRocco MT, Gentry LO, Lolans K, Quinn JP, et al. Prevalence of AmpC over-expression in bloodstream isolates of Pseudomonas aeruginosa. Clin Microbiol Infect. 2007;13(4):413-8. PMID: 17359326 DOI: 10.1111/j.1469-0691.2006.01674.x

12. Wayne PA. CLSI. Performance standards for antimicrobial susceptibility testing; twenty-fifth informational supplement. Wayne, PA: CLSI Document M100-S25, Clinical and Laboratory Standards Institute; 2015.

13. Li Y, Li Q, Du Y, Jiang X, Tang J, Wang J, et al. Prevalence of plasmid-mediated $A m p C \beta$-lactamases in a Chinese university hospital from 2003 to 2005: first report of CMY2-type AmpC $\beta$-lactamase resistance in China. J Clin Microbiol. 2008;46(4):1317-21. PMID: 18305137 DOI: 10.1128/JCM.00073-07

14. Yayan J, Ghebremedhin B, Rasche K. Antibiotic resistance of Pseudomonas aeruginosa in pneumonia at a single university hospital center in Germany over a 10-Year Period. PloS One. 2015;10(10):e0139836. PMID: 26430738 DOI: 10.1371/journal.pone.0139836

15. Berrazeg M, Jeannot K, Ntsogo Enguéné VY, Broutin I, Loeffert S, Fournier D, et al. Mutations in $\beta$-lactamase ampc increase resistance of Pseudomonas aeruginosa isolates to antipseudomonal cephalosporins. Antimicrob Agents Chemother. 2015;59(10):6248-55. PMID: 26248364 DOI: 10.1128/AAC.00825-15

16. Buchunde S, Mendiratta DK, Deotale V, Narang $P$. Comparison of disc and MIC reduction methods with polymerase chain reaction for the detection of metallo-betalactamase in Pseudomonas aeruginosa. Indian J Med Microbiol. 2012;30(2):170-4. PMID: 22664432 DOI: 10.4103/0255-0857.96683

17. Zhu B, Zhang P, Huang Z, Yan HQ, Wu AH, Zhang GW, et al. Study on drug resistance of Pseudomonas aeruginosa plasmid-mediated AmpC beta-lactamase. Mol Med Rep. 2013;7(2):664-8. PMID: 23241821 DOI: $10.3892 / \mathrm{mmr}$. 2012.1235

18. Juan C, Maciá MD, Gutiérrez O, Vidal C, Pérez JL, Oliver A. Molecular mechanisms of $\beta$-lactam resistance mediated by ampc hyperproduction in Pseudomonas aeruginosa clinical strains. Antimicrob Agents Chemother. 2005;49(11): 4733-8. PMID: 16251318 DOI: 10.1128/AAC.49.11.47334738.2005

19. Reuland EA, Hays JP, de Jongh DM, Abdelrehim E, Willemsen I, Kluytmans JA, et al. Detection and occurrence of plasmid-mediated $A m p C$ in highly resistant gram-negative rods. PLoS One. 2014;9(3):e91396. PMID: 24642853 DOI: 10.1371/journal.pone.0091396

20. Hemati S, Azizi-Jalilian F, Pakzad I, Taherikalani M, Maleki A, Karimi S, et al. The correlation between the presence of quorum sensing, toxin-antitoxin system genes and MIC values with ability of biofilm formation in clinical isolates of Pseudomonas aeruginosa. Iran J Microbiol. 2014;6(3):133-9. PMID: 25870745 